\title{
Visión urbana de la Ciudad de Choluteca en Honduras para el Año 2034
}

Johana Marcela Norori Solís

Víctor Baquedano Juan Ángel Del Cid

\section{Resumen}

En el marco del convenio existente entre la Universidad Nacional Autónoma de Honduras y Visión Mundial, el Observatorio Universitario de Ordenamiento Territorial de la Facultad de Ciencias Espaciales desarrolló, entre los meses de junio a octubre del año 2015 , un estudio de prospectiva urbana para la ciudad de Choluteca. El proyecto se desarrolló en dos fases: 1) Diagnóstico de la ciudad con recopilación de información de fuentes secundarias y datos obtenidos en gira de reconocimiento territorial, además de información resultante en talleres donde se aplicaron encuestas a los actores claves involucrados en el proceso y se hizo uso de cartografía y ortofotos de la ciudad de Choluteca; que sirvieron para identificar los principales problemas y potencialidades de la ciudad desde las dimensiones de los enfoques de ambiente, socio-economía y urbanismo e infraestructura. Así mismo se evaluaron los recursos con que cuenta la ciudad y se analizó como maximizar su potencial, teniendo como resultado final unasíntesis de problemas y potencialidades, que junto a una serie de indicadores que se determinaron permitieron conocer la situación actual que enfrenta la ciudad. Toda esta información de la fase de diagnóstico fue utilizada para generar un Modelo Urbano Actual de la ciudad de Choluteca. Posteriormente se trabajó la fase de 2) Prospectiva: donde se evaluaron las condicionantes al crecimiento de la ciudad y se construyeron los tres escenarios de prospectiva al año 2034, plasmando cartográficamente la visión futura de crecimiento tendencial, una visión de crecimiento óptima y la construcción final de un escenario intermedio construido en consenso con los actores claves que participaron en el proyecto.

Palabras clave: Choluteca, Diagnóstico Territorial, Prospectiva Urbana. 


\section{Abstract}

Under the existing arrangement between the Universidad Nacional Autónoma de Honduras and World Vision, the Faculty of Spatial Sciences, through University Observatory the Land Use Planning, developed between the months of June to October 2015, a study of urban prospective for Choluteca city. The project was developed in two phases: 1) Diagnosis of the city with secondary information and information from territorial recognition, in addition to resulting information in workshopswhere surveys were applied to key stakeholders involved in the process and use of mapping and orthophotos of the city of Choluteca; It was possible to identify the main problems and potentials of the city in the dimensions of approaches: environmental, socio-economics and urbanism and infrastructure. Also the resources of the city were analyzed and how they could take advantage of better way; as a result, was obtained a synthesis of problems and potential together with a series of indicators, that allowed to know the current situation facing the city, generating with all this information a current urban model of Choluteca city. Later, we worked in phase 2) Prospective: where constraints to the growth of the city were evaluated and also built the three scenarios foresight for year 2034, cartographically was reflected the future vision of trend growth, a vision of optimal growth and finally it built an intermediate stage in consensus with stakeholders involved in the project.

Key words: Choluteca, Territorial Diagnosis, Urban Prospective.

Johana Marcela Norori Solís, (johana.norori@unah.edu.hn), Víctor Baquedano, Juan Ángel Del Cid, Facultad de Ciencias Espaciales, Universidad Nacional Autónoma de Honduras. 


\section{INTRODUCCIÓN}

Honduras, al igual que el resto de países Centroamericanos, se encuentra ubicado en una zona geográfica altamente vulnerable ante los fenómenos naturales que se presentan, y esto sumado a la falta de planificación territorial que existe en el país, conlleva a tener un desarrollo no sustentable en el territorio que impacta en malas condiciones de vida para la mayoría de sus habitantes; entre los problemas que se presenta por la inadecuada planificación del territorio tenemos los siguientes:

- Desequilibrio territorial generando ciertas regiones que concentran gran parte de la actividad socio-económica del país mientras otras permanecen con un bajísimo nivel de desarrollo; es decir que se están potencializando las zonas aledañas a las principales arterias de comunicación del país, (eje central, carretera norte y carretera panamericana) y se están sub-desarrollando las regiones periféricas del país, en especial la oriental y occidental.

- Existe también un desequilibrio ciudad-campo o espacio urbano y espacio rural e ignorancia de los riesgos en la localización de actividades y usos del suelo, mezclando inadecuadamente los usos del suelo, generándose conflictos entre actividades y sectores; es decir que en el territorio se traslapan los distintos usos: agrícolas, industriales, urbanísticos, comerciales, infraestructuras etc. sin ningún tipo de criterio de localización ni planificación, de esta manera coexisten industrias en áreas, generando contaminación, ruido, problemas de tráfico etc. o zonas comerciales en zonas no aptas, desarrollos turísticos en zonas urbanas de baja calidad, ciudades con condiciones de ruralidad, donde no se cubren los servicios mínimos: agua, luz, teléfono, calles asfaltadas, infraestructuras en lugares no adecuados con otros usos entremezclados como los urbanísticos, logísticos y comerciales etc., lo anterior genera un mosaico desordenado y caótico de usos y actividades, que estrangula el desarrollo de las ciudades y del país.

- Tenemos también problemas de regionalización y descentralización del país: y es que Honduras enfrenta una baja descentralización efectiva que existe en los niveles administrativos inferiores, es decir, departamento y municipio, así como la desintegración de los planes de desarrollo municipal, ya que la mayoría busca desarrollar todas las facetas socioeconómicas, obviando las ventajas comparativas que unos municipios tienen sobre otros, además tenemos dificultades territoriales para dotar de equipamientos y servicios públicos; y es que por las características de dispersión del sistema de asentamientos de Honduras se tiene una gran cantidad de pequeñas aldeas 
(más de 2,400) y caseríos que inviabiliza la posibilidad de que el Estado pueda dotarlos y atenderlos con los equipamientos y servicios necesarios.

- Existe descoordinación de los organismos públicos, los organismos financieros y cooperantes; y en muchas ocasiones queda al descubierto que el Estado no tiene bien delimitadas las funciones y roles de las instituciones públicas, ya que muchos entes Estales tienen conflictos entre sus competencias; además existe una mezcla y superposición entre los organismos donantes, cooperantes y financieros; de tal manera que se repiten proyectos similares en una misma zona del territorio por distintos cooperantes, mientras otras áreas del país quedan sin intervención.

- El mal uso de los recursos naturales es otro de los graves problemas a solucionar entre los que destacan: ocupación indiscriminada del suelo, deforestación, contaminación deaguas superficiales y subterráneas, incendios, acumulación de basuras de una manera espontánea y sin control, localización de cultivos de granos básicos en zonas montañosas de fuertependiente, y disminución de laflora yfauna autóctona, la destrucción de los manglares y arrecifes coralinos.;

- Otro problema es que no existe una política preventiva y correctora de riesgos naturales, ni un mapa de zonas de riesgos detallado, y otras cuestiones transversales: como pobreza, falta de acceso a la tierra etc., hace que parte de los desarrollos humanos espontáneos (infraviviendas y viviendas de escasos recursos principalmente) se ubiquen en zonas de riesgo, lo cual impacta que ante la aparición de una catástrofe natural, como ya se vio en el pasado ( Huracanes Fifí y Mitch etc.), ocurran pérdidas enormes al país (vidas humanas, infraestructuras, viviendas, etc.).

Toda esta problemática que enfrenta el país debe irse solventando con una adecuada planificación del territorio, una activa participación de los ciudadanos y sobre todo la voluntad política. Se requiere que tomemos acciones inmediatas para poder planificar a futuro ciudades que sean sostenibles y que permitan mejorar la calidad de vida de todos los ciudadanos.

Por otro lado, Visión Mundial tiene dentro de su área de intervención nueve barrios de la ciudad de Choluteca, y en su experiencia han podido identificar problemas de planificación territorial que están impactando negativamente en los pobladores de estos barrios. Se observó un crecimiento desordenado de la ciudad en zonas que no son aptas para ser habitadas, así como desigualdad en la distribución de los equipamientos sociales y servicios básicos. 
Por lo cual solicitaron a personal docente de la Facultad de Ciencias Espaciales de la UNAH que realizaran un estudio de diagnóstico de la situación actual de Choluteca y que se elaborará un escenario futuro para el año 2034 que permita tener una ciudad ordenada, con planificación territorial, donde existan condiciones dignas para todos sus habitantes y con un desarrollo sostenible.

\section{METODOLOGÍA}

Es importante definir el término de Prospectiva apoyándonos en las definiciones de distintos autores: "La afirmación fundamental de la prospectiva es que hay varios futuros posibles. Comprender su significado y alcance resulta indispensable para visualizar el eje central de esta disciplina que construye escenarios futuros de largo plazo de la sociedad, las regiones y las organizaciones (Ramírez, 2004). La Prospectiva parte del principio lógico e indispensable que el futuro aún no existe y "se puede concebir como un realizar múltiple" (Jouvenel, 1968) que "depende solamente de la acción del hombre" (Godet, 2000). Por esa razón, la persona puede construir el mejor futuro posible, tomando las decisiones correctas en el momento apropiado. Existen muchos futuros posibles, aunque en el momento unos pocos tienen las mayores probabilidades de ocurrencia. La prospectiva nació y se ha desarrollado en permanente batalla con posiciones escépticas, deterministas 0 fatalistas acerca del futuro. Es un campo de investigación interdisciplinario que surge a finales de los 50' del siglo pasado, como respuesta a una sensación muy generalizada de aceleración del tiempo histórico y de percepción del futuro como riesgo. Se le concibe como herramienta de planeación con el propósito de incrementar la capacidad del ser humano de prever y modelar el desarrollo futuro de las sociedades.

No hay consenso respecto de sí la prospectiva es una ciencia (Serra, 2004). ¿Cómo puede existir una ciencia que no tiene objeto? Para muchos la respuesta es simple: no puede, el futuro no existe, y por definición no puede existir, ya que en el momento en que se concreta deja de serlo. El futuro es un concepto mental, un constructo social, por tanto, la prospectiva puede aspirar a ser una disciplina humanística, como la filosofía, por ejemplo, pero no una ciencia. Siendo ello cierto, hay matices, pues parte de la crítica se puede extender también a la mayoría de las ciencias sociales. A modo de ejemplo la historia acepta que su objeto, es el pasado, el que ya no existe, pero no impide que la historia analice documentos, restos y registros que han llegado hasta hoy. Por lo tanto, el criterio del objeto no puede ser determinante. En segundo lugar, la pretensión de cientificidad de la prospectiva se 
relaciona más con su empeño en estudiar el futuro mediante el método científico que con el estricto cumplimiento de los criterios para merecer el calificativo de ciencia. Ciertamente el futuro no existe, pero se tiene alguna información sobre él. Se sabe el carácter cíclico de muchos fenómenos. Se puede proyectar informaciones pasadas y/o presentes en el futuro (extrapolación de tendencias), cuyo caso más obvio son las previsiones demográficas. Por último, están los propios proyectos, esperanzas y temores, que guían la actividad presente; son nuestras imágenes de futuro, todos las tenemos y la prospectiva las estudia, clasifica y procesa. Son el verdadero objeto de estudio de la prospectiva de forma análoga a lo que son los vestigios históricos para la historia. Para zanjar el asunto de la cientificidad se puede decir que, si bien la prospectiva carece de objeto real, dispone de objetos que le permiten emprender el estudio de los futuros posibles con el rigor y la sistemática que se suponen en la ciencia Serra, 2004).

La Prospectiva trata de atraer y concentrar la atención sobre el futuro, imaginándolo a partir de éste y no del presente. Para Miklos y Tello (2000), en la prospectiva la visión del porvenir hacia el presente, rebasa la proyección exclusiva de tendencias, para diseñar y construir alternativas que permitan un acercamiento progresivo al futuro deseado. La Prospectiva no es literalmente una utopía, al respecto De Venanzi (2000), señala que: "Así pues, el futuro no se percibe ya como un guion escrito que hay que representar, no sólo porque la selección personal dentro de la complejidad puede variar radicalmente, sino porque la necesidad histórica no es de tipo mecánico". Ciertamente, como primer paso lógico la Prospectiva usa los recursos de la utopía en cuanto "remontar el vuelo imaginativo", pero en el proceso creativo "articula esfuerzos concretos para transformar la realidad".

En planificación territorial se habla de la prospectiva estratégica como herramienta para promover la competitividad y el desarrollo integral de los habitantes. Sirve para articular el territorio con las dinámicas globales a través de estrategias nacionales, planes de desarrollo local y regional y los planes de ordenamiento territorial. La aplicación de la prospectiva estratégica a la planificación territorial de municipios, ciudades y naciones es la respuesta a la necesidad de solucionar y enfrentar los desafíos que los habitantes y sociedades en conjunto tienen cotidianamente en sus continuas transformaciones. La prospectiva permite visualizar el modelo territorial del futuro, mediante la construcción de escenarios, con la participación de los principales actores de la comunidad, implementando los talleres y utilizando técnicas especialmente diseñadas para tal fin.La Prospectiva es clave en la Planificación Territorial y se inserta en la etapa de modelación de los escenarios, para establecer el modelo de Territorio buscado por los actores. Es decir que a 
través de la Prospectiva se construyen los siguientes escenarios: tendencial, que marca la tendencia que puede seguir el territorio; óptimo que será aquella visión ideal que se podría lograr con el territorio si se tomarán todas las acciones políticas, económicas, sociales, ambientales, etc. que permitieran un verdadero desarrollo sostenible, aunque este escenario se vuelve utópico; y por último con la prospectiva se construye un escenario intermedio, es decir una visión más realista de lo que puede llegar a ser el territorio en un futuro, este escenario es determinante para lograr un mejor funcionamiento del territorio en el futuro, y por eso se construye con la participación de los actores claves, para que la población y las autoridades se adueñen de él y puedan contribuir a desarrollarlo en un futuro siguiendo planes de acción necesarios para su ejecución.

La fase de Diagnóstico Integral Multidimensional de la ciudad de Choluteca se centró en la investigación de fuentes secundarias de información, así como otros datos productos de la gira de reconocimiento territorial y entrevistas con actores claves, funcionarios de la administración local, actores de la sociedad civil y recolección de información secundaria, orientada hacia fuentes documentales y cartográficas.

Dentro de esta fase se realizaron dos talleres participativos, el primer taller fue realizado el 15 de julio del año 2015 y participaron veinte actores claves representados así: un representante de la Alcaldía de Choluteca, tres de Caritas, ocho representantes de los Comités de Emergencia Locales - CODELES de los barrios en donde está interviniendo Visión Mundial, un representante de Desarrollo Integral del Niño Adolescente y Familia - DINAF, un representante de la Cruz Verde, un representante del Instituto Nacional Agrario - INA, un representante de los Bomberos, dos representantes de la Mesa Nacional de Incidencia para la Gestión del Riesgo y dos representantes de Visión Mundial asignados a Choluteca; además de asistir los tres representantes de la Universidad Nacional Autónoma de Honduras - UNAH - que estaban desarrollando el estudio de Diagnóstico (al que llamaremos equipo investigativo). Y el segundo taller se realizó el 18 de agosto y se contó con la participación de veintiún actores claves: tres representantes de la Alcaldía de Choluteca, diez representantes de los Comités de Emergencia Locales - CODELES de los barrios en donde está interviniendo Visión Mundial, un representante del Instituto Nacional Agrario - INA, un representante de la Cruz Roja, un representante de los Bomberos, dos representantes de la Mesa Nacional de Incidencia para la Gestión del Riesgo, un representante del Centro Regional del Litoral Pacífico - CURLP y dos representantes de Visión Mundial asignados a Choluteca; además de asistir el equipo investigativo de la UNAH. 


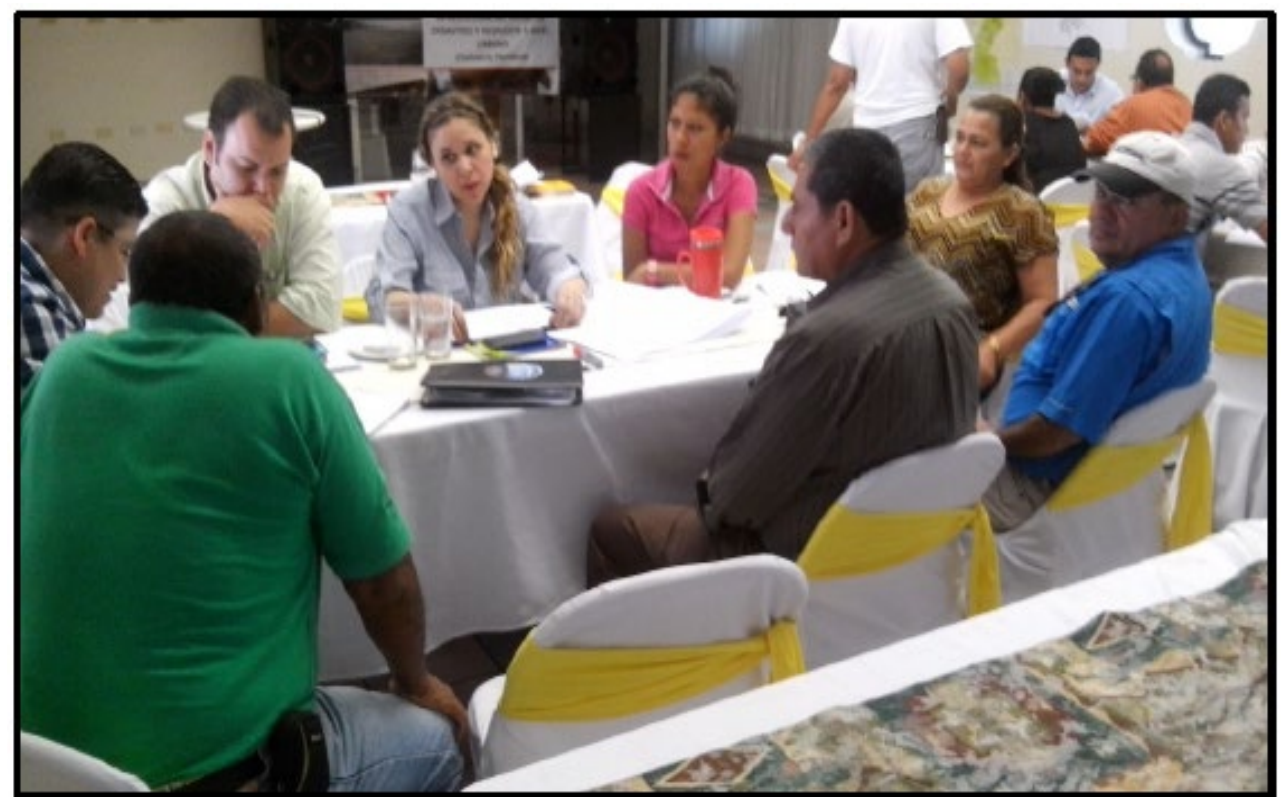

Figura 1. Mesa de trabajo Sector Ambiente

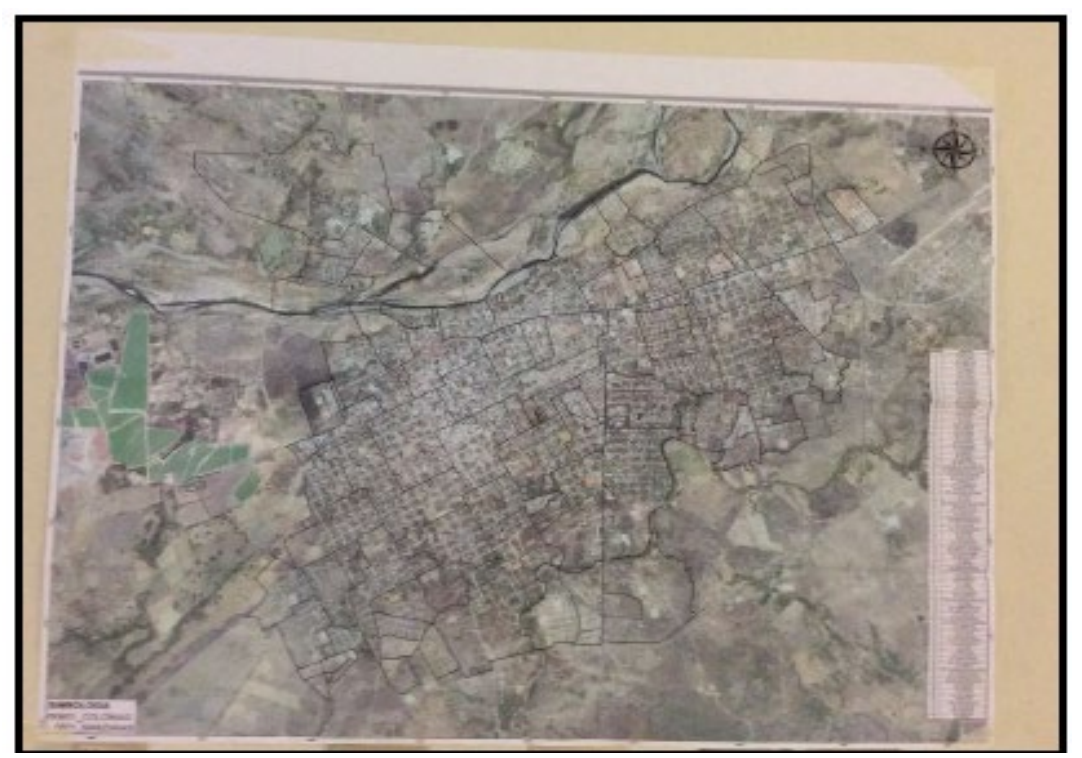

Figura 2. Ortofoto utilizada para la identificación de problemas en la ciudad de Choluteca 
El objetivo de estos dos talleres fue abordar, desde tres mesas grupales de trabajo, la situación que enfrenta la ciudad desde el punto de vista ambiental, de urbanismo e infraestructura y el punto de vista socioeconómico. Fue así como a través de encuestas se detectaron los problemas, potencialidades y se evaluaron las magnitudes de cada uno de ellos, realizando las siguientes actividades:

- Se identificó, caracterizó y jerarquizó los problemas, haciendo un ejercicio de semaforización.

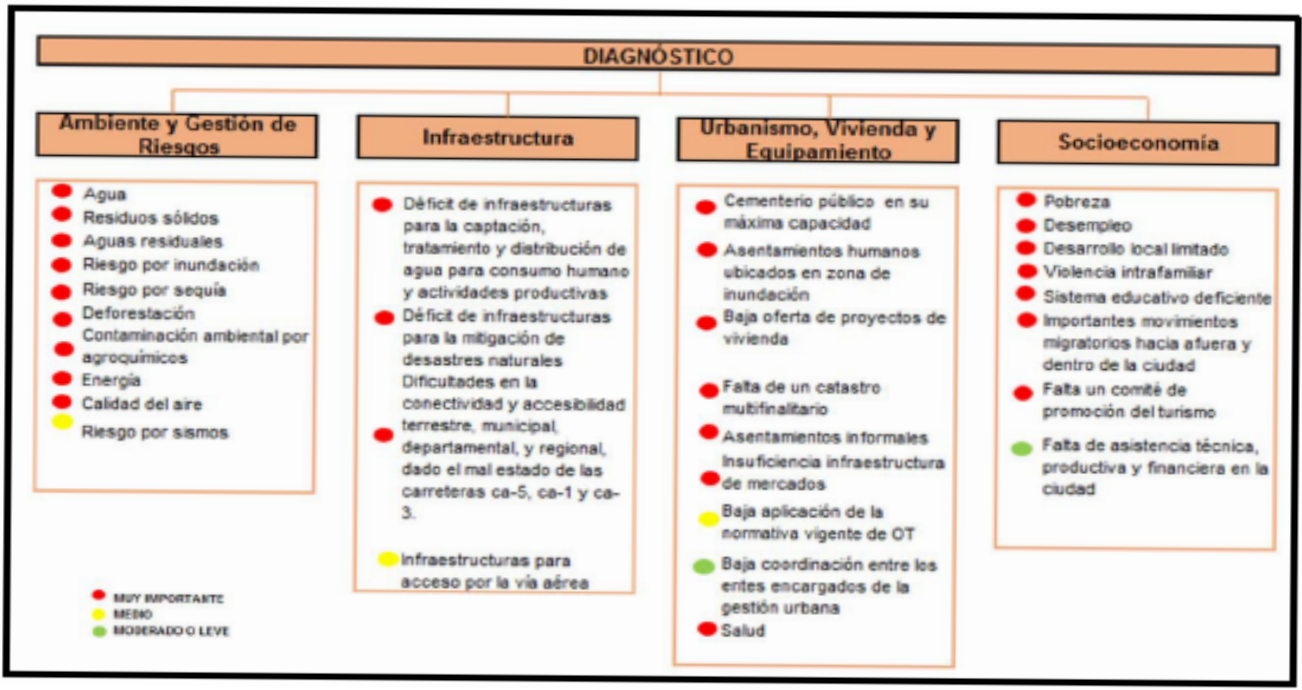

Figura 3. Diagrama multidimensional de problemas identificados en la ciudad de Choluteca a través del ejercicio de semaforización

- Se elaboraron fichas de los problemas urbanos encontrados por cada sector con el objeto de determinar las causas generales de estos problemas que permiten comprender la disfuncionalidad detectada, demostrando los efectos que generan estas falencias.

- Se localizaron los problemas dentro de la ciudad.

- Se identificaron potencialidades de la ciudad, las cuales fueron jerarquizadas haciendo uso del ejercicio de semaforización y se elaboraron las fichas para cada una de ellas. 


\section{DIAGNÓSTICO - POTENCIALIDADES}

Ambiente y Gestión de

Riesgos

Potencial energia sclar

Polencial hidrico

Potencial ecoturistico
Infraestructura

Su posición geográtca

Intraestructura generadora de energia solar
Urbanismo, Vivienda y

Equipamiento

Turismo colonial

Adecuado equipamiento de recreación

Existe un POT
Socioeconomia

Población joven

Ubicación estrategica que permite la

comercialziación de productos

- Voluntad politica en el Gobiemo Local

- Presencia e importanda de la participación activa de las iglesias y ONC'S

- Buena estructura de las organizaciones sociales.

Figura 4. Diagrama multidimensional de potencialidades identificadas en la ciudad de Choluteca

Seguidamente el equipo investigativo realizó el análisis de todos los sectores estudiados y se procedió a elaborar la síntesis para cada uno de los problemas y las potencialidades considerando que en suma conforman el sistema urbano de la ciudad de Choluteca. Seguidamente se establecieron cuáles son las causas y los efectos de los problemas que enfrenta la ciudad, valorando cada uno de ellos, con el fin de establecer cuáles son los más críticos; así mismo se evaluaron los recursos con que cuenta la ciudad y como se pueden aprovechar de mejor forma sus potencialidades. Posteriormente se realizó una síntesis de los problemas y las potencialidades, para ello se estableció una matriz de problemas relacionados que junto a una serie de indicadores que se determinaron, que permitieron conocer la situación actual que enfrenta la ciudad, generando con toda esta información el Modelo Urbano Actual de la ciudad de Choluteca.

La segunda parte de la investigación consistió en validar a través de un taller participativo con los actores claves mediante la aplicación de encuestas cualitativamente la matriz con las potencialidades y debilidades de la ciudad como resultado del análisis de los indicadores evaluados cuantitativamente en la primera fase. Y se aplicó la prospectiva para construir los escenarios tendencial y óptimo; realizando finalmente un taller participativo donde se construyó el escenario de prospectiva intermedio para la ciudad de Choluteca al año 2034. 


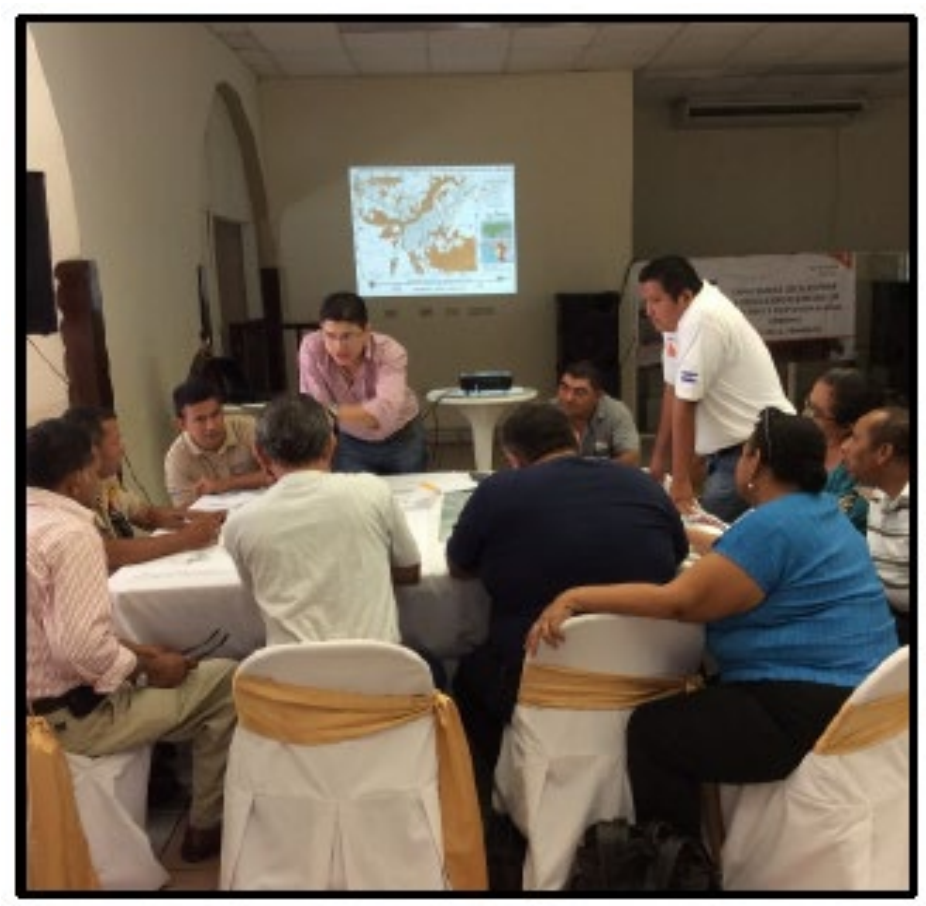

Figura 5. Taller de validación de Fase de Prospectiva

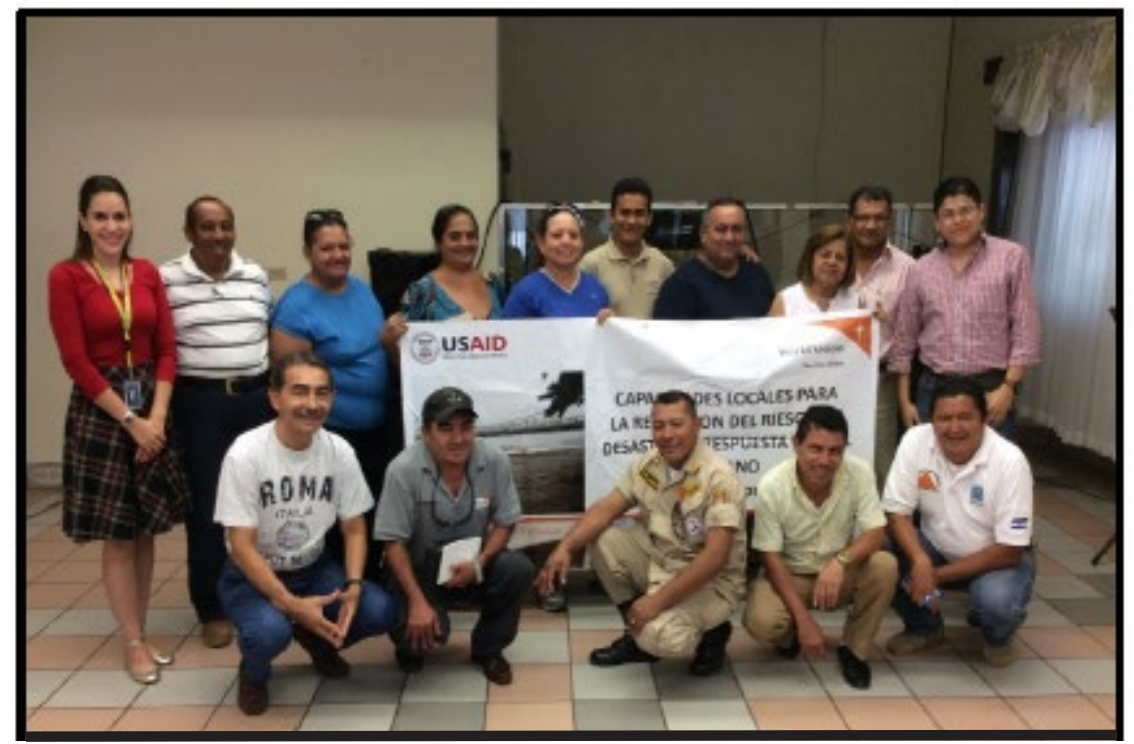

Figura 6. Colaboradores de UNAH, World Vision, Alcaldía de Choluteca, y participantes de la sociedad civil 
Esta fase consiste, en visualizar el territorio hacia el futuro (20 años) desde tres escenarios: -Tendencial, visualizando el crecimiento del territorio, sin ninguna intervención o acciones para cambiarlo, dejar que crezca con las condiciones de desarrollo con que cuenta en la actualidad. - Optimo, es el que debería tener el territorio con las mejores condiciones del desarrollo, a través de una planificación adecuada a la realidad del territorio, y con una buena gestión de los recursos para alcanzar los objetivos propuestos para un crecimiento y desarrollo sostenible y ordenado. - Intermedio, es el escenario concertado por todos los actores implicados de forma directa e indirecta en el territorio, a través de un consenso en mesas de participación ciudadana, para la planificación y gestión consiente de las condiciones del territorio y su población actuales. Para este escenario, se requiere la integración o concertación de los escenarios anteriores, por lo que se decidió utilizar un $60 \%$ de lo propuesto en el escenario optimo, y un $40 \%$ del escenario tendencial.

- Las actividades desarrolladas en esta fase fueron:

- Definición de condicionantes al desarrollo urbano

- Desarrollo de los escenarios alternativos o variantes

- Desarrollo de la alternativa de consenso

- Modelo Urbano Futuro o imagen deseada

\section{RESULTADOS}

Para obtener el Modelo Urbano Actual se analizaron los resultados obtenidos en la síntesis de problemas y potencialidades partiendo del diagnóstico de los diferentes sectores: ambiente, urbanismo e infraestructura y socio economía. 


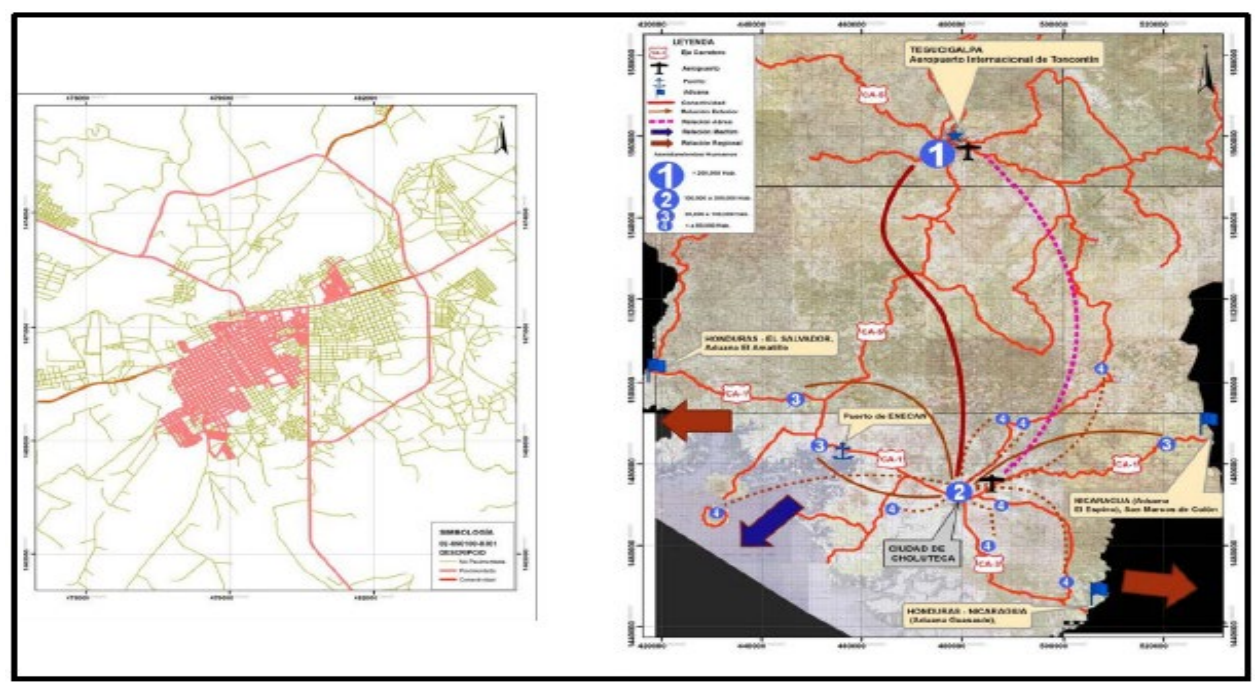

Figura 7. Análisis de conectividad de la ciudad

Luego se determinaron cuáles son las condicionantes al desarrollo urbano en la ciudad de Choluteca, entre las que podemos mencionar las siguientes:

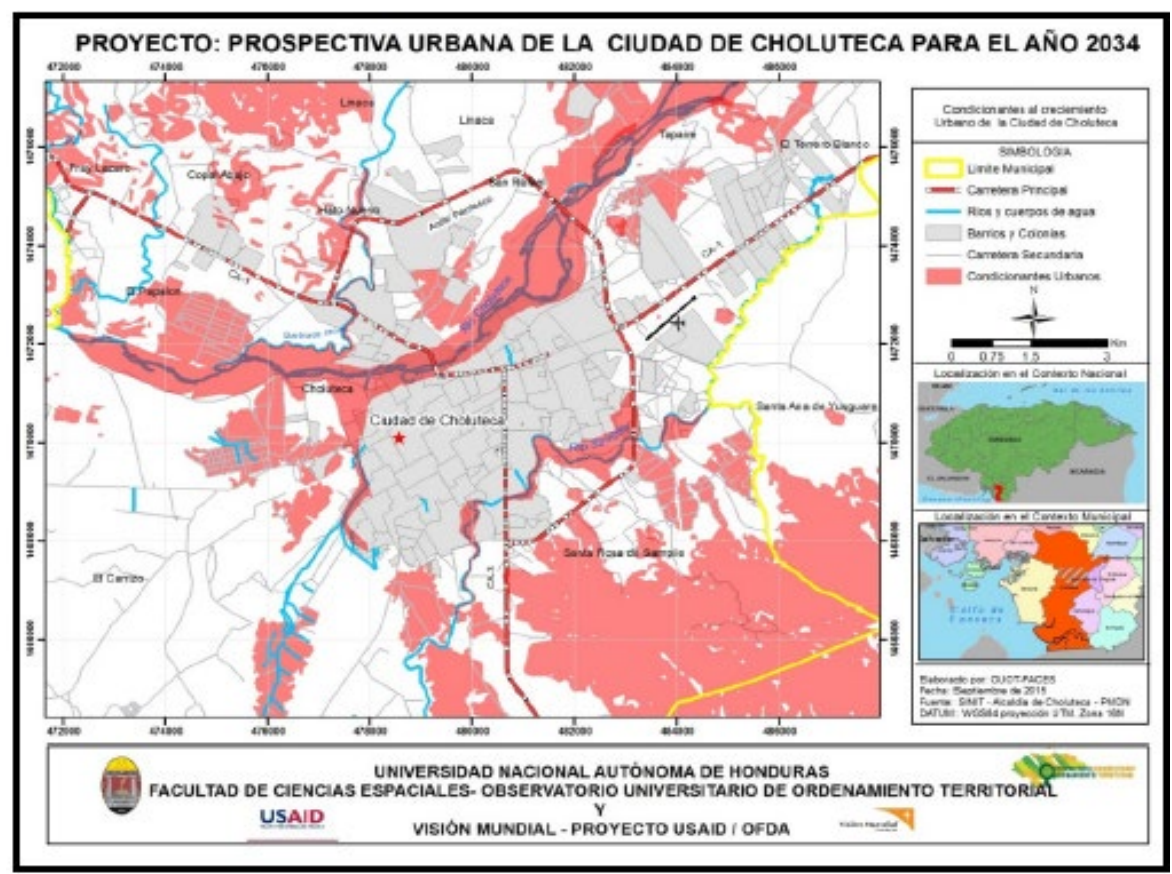

Figura 8. Condicionantes al crecimiento en la ciudad de Choluteca 
- Al norte de la ciudad de Choluteca se encuentra el rio Choluteca, con un flujo de agua en dirección Noreste, Suroeste produciendo una amenaza latente de inundación en los Barrios Las arenas, Brisas del Rio, Morazán, parte baja de Los Mangos, Corbeta, La Cruz, Gualiqueme y Playas de Iztoca.

- La quebrada Iztoca atraviesa de norte a sur el barrio del mismo nombre, produciendo un alto riesgo de inundación en dicho barrio.

- Al sur de la ciudad se localiza el rio Sampile, el cual tiene un flujo de agua en dirección Noreste, Sur, generando una amenaza en los siguientes barrios, Santa Rosa de Sampile, Bo. Gracias a Dios, Bo. Sagrado corazón, Bo.21 de octubre, y Las Vegas.

Amenaza de deslizamiento o pendientes mayores a $30 \%$

La ciudad de Choluteca se encuentra dentro de la planicie costera del pacifico por lo que las pendientes en la mayoría de su territorio son inferiores a $20 \%$, sin embargo, cuando las pendientes sobrepasan el 30\% sumado a las condiciones climatológicas de lluvias intensas, y la alta sismicidad de la zona se pueden producir deslizamientos, ocasionando daños a la infraestructura que ahí se construya.

- Se han identificó zonas de alta pendiente al norte de la colonia Unidas, Arias Lagos, entre el anillo periférico y la Col. Villa de Jerez, al norte de la Col. Nuevo Limón de La Cerca.

- Al norte, en las montañas que bordean la ciudad de Choluteca.

- Al sur de la ciudad en dirección a Santa Rosa de Sampile, se encuentra una cadena de cerros que constituyen un importante condicionante desde el punto de vista de deslizamiento de laderas.

\section{Zonas agroindustriales}

- Al norte de la ciudad entre el anillo periférico y la col. Villa de Gualiqueme existen 2 zonas agroindustriales 0 de cultivos semi-tecnificadas.

- Al Noreste del área urbana en dirección a San Marcos de Colon, hay 2 zonas agroindustriales, la primera al norte de la col. La Felicidad y Col. Villa de Jerez y la segunda al norte de la col. Junior y Col. El establo.

- Al Noroeste de la ciudad, hay 1 zona agroindustrial importante ubicada al sur de la carretera panamericana y la Col Unidas. 
- Al este de la ciudad y tomando la calle que conduce hacia el municipio de Marcovia, existe una zona agroindustrial significativa.

- Al sur de la ciudad específicamente al oeste de la carretera hacia la aduana Guasaule, se sitúa una zona agroindustrial importante.

- Al Sur-Este de la cuidad de Choluteca y del río Sampile se halla otra zona agroindustrial.

Otra zona de restricción importante podría ser alrededor del aeródromo de Choluteca, ya que en un futuro podría representar un medio de infraestructura de transporte muy importante en el desarrollo de la cuidad y de la región.

En la fase de Prospectiva se establecieron los tres escenarios en el horizonte del año 2034: Tendencial, Optimo e intermedio; para ello se determinó la proyección de la población y su densidad poblacional por área de ocupación, es decir, el área donde se asentará la población proyectada. A continuación, se muestra como se realizó el cálculo de la población proyectada para el año 2034; para ello se tomó como base los datos censales históricos del Instituto Nacional de Estadísticas.

Tabla 1. Datos Censales INE 2013.

\begin{tabular}{|l|l|}
\hline AÑO CENSAL & POBLACIONN \\
\hline 1988 & 56,573 \\
\hline 2001 & 76,135 \\
\hline 2013 & 107,462 \\
\hline
\end{tabular}




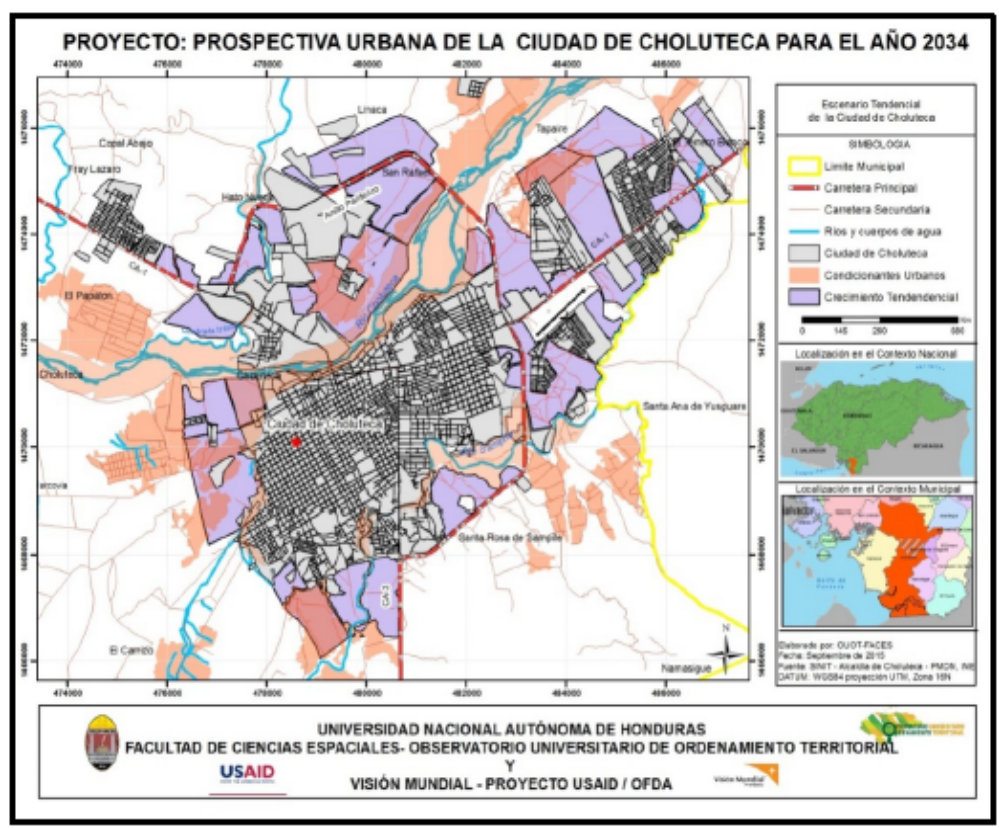

Figura 9. Escenario de crecimiento Tendencial

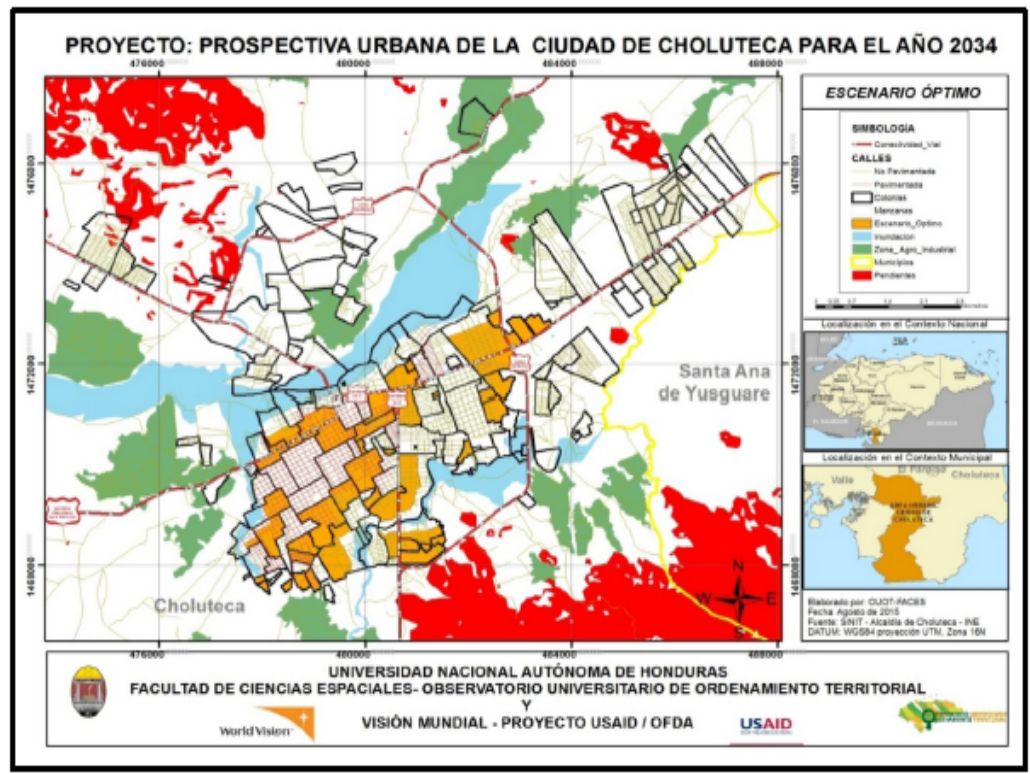

Figura 10. Escenario de crecimiento Optimo 


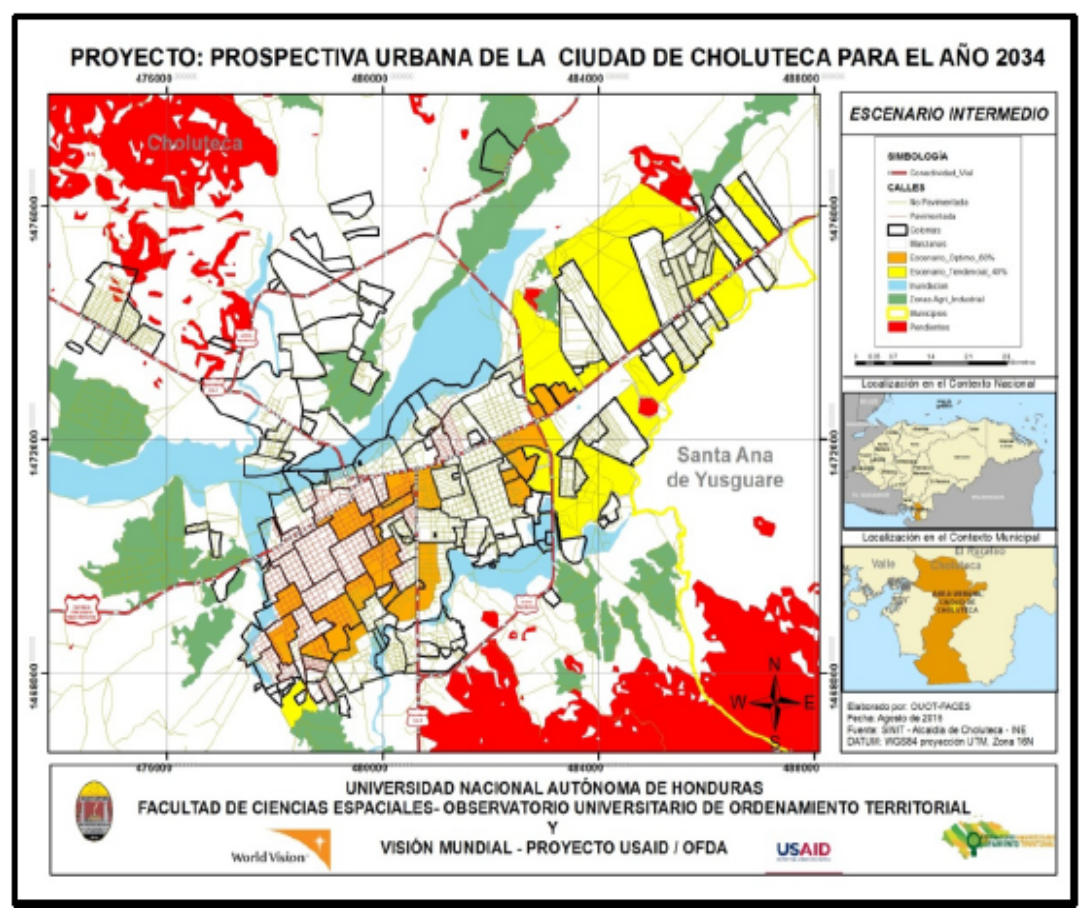

Figura 11. Escenario de crecimiento Intermedio

\section{DISCUSIÓN}

\section{Escenario Tendencial Ciudad de Choluteca}

El escenario tendencial es únicamente teórico, permitirá observar el desarrollo futuro de la ciudad de Choluteca, siguiendo los patrones que actualmente se dan y respetando al mínimo las normativas de ordenamiento territorial, la tendencia será seguir el patrón que actualmente se manifiesta en la ciudad, en donde las zonas más desfavorecidas incrementarán su mala situación, mientras que las zonas favorables seguirán mejorando levemente. Este escenario servirá como límite mínimo no deseado en la prospectiva de crecimiento de la ciudad al año 2034.

La población estimada para la ciudad de Choluteca al año 2034, es de 184,350 habitantes (datos censales, INE, 2013), actualmente la densidad poblacional de la ciudad es de 34 habitantes por hectárea, se estima que la tendencia seguiría igual, por lo que la densidad de población al año 2034 sería de 34 hab/ha, debido a este baja densidad y al crecimiento desordenado en forma dispersa y lineal, la ciudad 
aumentara un total de 2,271 hectáreas para tener la capacidad de acogida a esta nueva población y con una densidad baja.

- En la parte norte de la ciudad, los barrios nuevos se encajarían dentro del áreas de inundación aumentando la vulnerabilidad de la ciudad, también sería difícil dotarlos de equipamiento básico y social

- En la parte oeste los patrones de progresión de los asentamientos son acrecer en zonas inundables e invadir zonas agroindustriales reflejando una densificación de estos asentamientos hacia la carretera salida a Marcovia.

- En la zona sur de la ciudad, el crecimiento sería hacia al lado derecho de la carretera que conduce a Guasaule, invadiendo áreas de inundación del rio Sampile y zonas agroindustriales.

- Mientras que hacia la parte este, salida a San Marcos de Colon la densificación seguirá el patrón de dirección de dicha carretera

- Mientras no se aplique las medidas correctivas y normativas de uso del suelo, y se les de alternativas de habitabilidad digna, será imposible reasentar los habitantes que actualmente viven a orillas del rio Choluteca.

\section{Componente ambiental y gestión de Riesgos}

Debido a los patrones de crecimiento inadecuados, la ciudad se expandirá desordenadamente, hacia la periferia y a orillas de los principales ejes carreteros, prevaleciendo los asentamientos humanos con equipamiento básico mínimo, donde la falta de alcantarillado sanitario y la disposición final de las aguas residuales serán un foco de contaminación de los efluentes como ser el Rio Choluteca, Rio Sampile y quebrada Iztoca, en tanto el deficiente sistema de agua potable de calidad incrementara los casos de enfermedad dentro de la población, adicionalmente la ausencia de mecanismos de recolección de desechos sólidos obligara a sus pobladores a seguir con las practicas poco amigables con el ambiente que contaminan tanto el suelo aledaño como las fuentes de aguas subterráneas y superficiales como el río Choluteca Rio Sampile.

- En la zona norte de la ciudad entre el anillo periférico y el Rio Choluteca se ubicarán nuevos asentamientos en zonas de inundación. 
- En tanto los barrios y colonias ubicados en zonas susceptibles a inundacón tanto a orillas del Rio Choluteca y Río Sampile, seguirán ahí sin ningún cambio y con pocas medidas de prevención y mitigación de desastres.

- Datos de la organización Meteorológica Mundial, que afirman que los fenómenos atmosféricos que afectan Honduras, que limitan la cantidad de agua y que son producto del cambio climático global, como por ejemplo el fenómeno de la sequía que afecta grandemente a la nación y la ciudad de Choluteca, los problemas de agua potable se agudizarán, debido a la falta de previsión en la construcción de fuentes de captación y potabilización del agua para consumo humano.

- El crecimiento urbano será hacia las zonas periféricas de la ciudad y que antiguamente fueron zonas agroindustriales, aumentando el riesgo de contaminación debido a agroquímicos remanentes en el subsuelo, ya que al momento de perforar pozos de agua potable el agua no será apta para uso humano, provocando incidencias en la salud de sus beneficiarios.

- La deforestación a la orilla del rio Choluteca y rio Sampile seguirá, en consecuencia y producto de la erosión la reducción de la vegetación afectará considerablemente provocando la pérdida de biodiversidad ambiental de la zona, también aumentará el azolvamiento del río aumentando la vulnerabilidad de la ciudad de Choluteca.

\section{Componente de Infraestructuras}

- En los principales ejes carreteros CA1 y CA3, se continuará con el mantenimiento de la red vial pavimentada, pero sin presentar mejoras significativas principalmente en el eje carretero CA3 que conduce a la aduana Guasaule, sin importar que estas vías representan un importante flujo de mercancías a nivel regional y centroamericano, además muchos tramos están totalmente dañados y es necesario su reconstrucción total.

- La red vial pavimentada dentro de la ciudad crecerá levemente y el mantenimiento en sus principales avenidas y bulevares seguirá, sin embargo, la red vial interna principalmente en los barrios periféricos no mejorara sus calzadas continuarán siendo de terracería. 
- El aeródromo pudo representar una importante infraestructura de transporte que facilitaría las actividades comerciales y de exportación de la zona, sin embargo, el crecimiento desordenado absorbió las posibles áreas de expansión de la terminal aérea limitando la pista solo para labores de aviones pequeños.

- La infraestructura de alcantarillado sanitario crecerá poco, limitándose dentro del centro de la ciudad, será imposible dotar de infraestructura de servicios básico a las zonas que crezcan alejado del área consolidada de la ciudad.

- Del mismo modo la infraestructura de agua potable en cuanto a captación almacenamiento y distribución, no suplirá la demanda de la población, dado el crecimiento poblacional seguido de la incorporación de nuevas viviendas al sistema, a esto se le sumará el deterioro de la red la cual estará al final de su vida útil.

- Con la adquisición de más unidades y la incorporación de estas a la red de recolección de desechos sólidos, la cobertura dentro del centro de la ciudad aumentara, en tanto los barrios y colonias periféricos seguirán sin el servicio, el botadero municipal estará llegando al final de su periodo de servicio.

\section{Componente Urbanismo Vivienda y Equipamiento}

- La falta de cumplimiento de normativas de ordenamiento territorial y la descoordinación interinstitucional, serán una de las causas de que la estructura urbana se deteriore con la aparición y consolidación de asentamiento en zonas desfavorables (áreas inundables), se pronostica un crecimiento acelerado en las principales vías de comunicación terrestres, CA1, carretera hacia Tegucigalpa y salida a San Marcos de Colon, Carretera CA3 rumbo a la Aduana Guasaule, y Carretera que conduce a Marcovia.

- La aparición y consolidación de asentamientos a la orilla de las principales vías de comunicación terrestre vendrá a aumentar los problemas de invasión en el derecho de vía limitando el tránsito de los vehículos, restringiendo las posibles ampliaciones y mejoras en los trazos geométricos de las carreteras, del mismo modo aumentando la posibilidad de accidentes vehiculares en ella.

- Debido a que la mayoría de terrenos en la ciudad de Choluteca son de carácter privado, no existe una política clara de vivienda básica para poder satisfacer la demanda cuantitativa y cualitativa de los asentamientos informales que 
seguirán creciendo, con los servicios básicos mínimos creando problemas ambientales sociales y de mala imagen urbana. El crecimiento de la vivienda social será limitado y poco.

- Los vendedores informales aumentaran debido a la falta de empleo e infraestructura de mercado la cual es muy antigua y no reúne los requisitos para albergar el creciente número de vendedores como ser el mercado San Antonio e Inmaculada Concepción, creando una mala imagen a la ciudad.

- El cementerio municipal será insuficiente, actualmente está casi lleno por lo cual si se sigue la tendencia en pocos años colapsará.

- En la ciudad seguirán creciendo las áreas verdes, pero sin crear un cinturón verde alrededor de ella, en especial a orillas del Río Choluteca y Sampile lo que mejoraría la imagen de la ciudad.

- El equipamiento recreativo dentro del centro de la ciudad seguirá igual, en las zonas periféricas de la ciudad este equipamiento mostrará un deterioro debido a la falta de mantenimiento.

- La planificación territorial seguirá igual, impidiendo desarrollar adecuadamente la ciudad, la falta de datos del territorio en todas sus dimensiones será grande generando pérdidas cuantiosas en concepto de impuestos todo esto consecuencia de la falta de un catastro multifinalitario.

\section{Componente Socioeconómico}

- La ciudad de Choluteca seguirá siendo una ciudad de prestación de servicios, sin embargo, la falta de dinamismo y gestión en cuanto a planes y propuestas adecuados de crecimiento económico limitar el atractivo de las pequeñas, medianas y grandes empresas, tanto nacionales como extranjeras, reduciendo grandemente la generación de empleos en la zona.

- Como consecuencia del crecimiento de los asentamientos informales, y la falta de empleo, aumentara el número de conflictos sociales debido a la tenencia de la tierra y aumento de delitos comunes.

- La falta de una política de incentivos y promoción hacia el atractivo turístico mantendrá el rubro en los niveles actuales los cuales son muy bajos comparados con el potencial turístico que tiene la ciudad especialmente su turismo colonial, 
la industria hotelera crecerá levemente pero no necesariamente debido al turismo si no a que Choluteca es un punto de convergencia estratégico entre dos fronteras internacionales.

- Debido a la construcción prevista de un hospital de especialidades la mejora en este sector será grande, sin embargo, el hospital regional pese a ser un importante centro asistencial y consecuencia de la falta de mantenimiento se encontrará en malas condiciones en cuanto a infraestructura básica, lo cual limitará la asistencia de hospitalizaciones generales.

- El sistema de educación pública y privada tanto a nivel básico, secundario y universitario seguirá creciendo en cantidad, pero existirán deficiencias en cuanto a infraestructura de calidad, infraestructura tecnológica y oferta de carreas técnicas afines a la productividad de la región.

- La organización, gestión y participación social de la población civil, no será la adecuada para poder formular propuestas acertadas en cuanto a propuestas de proyectos de inversión social, generando vacíos y zonas donde no llegan dichas inversiones por parte del estado y municipalidad.

\section{Escenario Óptimo, Ciudad de Choluteca}

Este es el escenario deseado, la imagen del territorio deseable por todos, donde se establecen los criterios necesarios para alcanzar los objetivos planeados.

Para la construcción de este escenario, se parte de la idea de tener a la disposición todos los recursos del territorio y la voluntad política, como ser: acciones inmediatas por parte de la autoridad y responsables en decisiones transcendentales para el territorio, recursos humanos, económicos, tecnológicos, de infraestructura, etc., todos ellos, orientados en solventar los problemas identificados, y aprovechar eficientemente las potencialidades, también previamente identificados, además de la implementación adecuada de las condiciones de desarrollo en cuanto a usos y políticas del territorio en el futuro. 


\section{Componente Ambiental y Gestión de Riesgos}

En este componente, el escenario óptimo establece el uso del suelo según su vocación propia, la cual deberá tener la ciudad y sus alrededores, con el fin de preservar las áreas con alto grado de conservación y condicionar aquellas áreas donde no se puede desarrollar la ciudad, ya sea por condiciones de protección ambiental, o por riesgo a desastres naturales.

En la ciudad se destacan cuatro usos del suelo de vocación urbano: Residencial (barrios y colonias con potencial a incentivar), Industrial (alrededores del área urbana desarrollada, y dentro del perímetro de control urbano), comercial (centro de la ciudad, mercados y en los ejes carreteros principales), áreas verdes (parques, centros deportivos, de recreación, etc.) y solares baldíos o desocupados (terrenos particulares sin ningún uso urbano).

Con la puesta en marcha y las acciones pertinentes al ordenamiento territorial de la ciudad, en relación a los usos del suelo urbano antes mencionados, sumado la concientización, participación de la población y el involucramiento institucional, se obtendrán los resultados ambientales siguientes:

- En cuanto al manejo de los desechos sólidos, aguas servidas, y la infraestructura adecuada para el tratamiento de estos, se logrará reducir al mínimo, la contaminación del suelo, de las aguas superficiales y subterráneas, así como también, la contaminación del aire, mediante la regulación de emisiones de $\mathrm{CO} 2$ y otros gases contaminantes.

- Protección y conservación de las principales fuentes de abastecimiento de agua potables, proporcionándole a la población un suministro de calidad, mediante los mecanismos y tratamientos estrictos de potabilización de las aguas superficiales y subterráneas.

- Implementación de un plan de protección y conservación de las riveras de los ríos Choluteca, Sampile, y quebrada Iztoca, proporcionándole a la ciudad, prevención y buena imagen urbana.

- Establecimiento ordenado de expansión y equipamientos adecuados de las áreas de desarrollo agroindustrial e industria manufacturera, haciendo uso sostenible de los recursos naturales con que cuenta la ciudad (agua, suelo, aire, biodiversidad, flora y fauna etc.). 


\section{Componente de Asentamientos Humanos}

La ciudad de Choluteca por ser la cabecera departamental, y la principal ciudad de la región sur del país, representa un principal polo de desarrollo en cuanto a actividades de comercio y prestación de servicios, por lo que la calidad de vida para sus habitantes, debe ser la más favorable en relación a equipamientos necesarios, con capacidad de demanda y respuesta, mediante una planificación urbana moderna, infraestructuras de calidad que sean funcionales, etc., por lo que, la distribución de su población asentada en barrios y colonias, debe ser la más óptima posible, para el buen aprovechamientos de sus espacios urbanos, fortaleciendo los asentamientos humanos a incentivar, desfavoreciendo los asentamientos humanos a desincentivar.

La población estimada para la ciudad de Choluteca en el escenario del año 2034, es de 184,543 habitantes (proyección de crecimiento de 2\% según INE 2013), con una densidad de 100 habitantes por hectárea, la cual se ha densificado en las áreas de menor densidad poblacional y las concerniente a solares sin habitar, correspondientes al área urbana consolidada para el año 2015, así como también, la población asentada en los principales ejes carreteros de la ciudad, de la forma siguiente:

- CA-1, de Choluteca hacia Tegucigalpa, sector noreste;

- CA-1, de Choluteca hacia San Marcos de Colon, ambos lados de la carretera, este como principal área de desarrollo residencial y comercial;

- CA-3, de Choluteca hacia El Triunfo, ambos lados de la carretera, en menor intensidad;

- Carretera de Choluteca hacia Marcovia, sector sur, representando un importante sector de desarrollo residencial, con ciertas limitaciones por las zonas de expansión agroindustrial y de inversión privada;

- Por último, el Anillo periférico, en sus alrededores, con restricción a las zonas industriales del sector noreste y sureste de la ciudad.

- Reubicación de los asentamientos ubicados en las aéreas propensas a desastres naturales, como ser: área de inundación de los ríos Choluteca y Sampile, y las áreas propensas a deslizamiento, en las zonas de altas pendientes, en la periferia de la ciudad. 
- Limitantes al desarrollo y crecimiento urbano residencial y comercial, en las áreas destinadas a la producción agroindustrial.

\section{Componente de Urbanismo, Vivienda y Equipamiento}

La ciudad crece de forma planificada,ordenada, estructuralmente eficiente, presentando un escenario urbanístico compacto en la distribución de los barrios y colonias, con una utilización adecuada de sus espacios urbanos, de acorde a la política del uso del suelo urbano implementado en la ciudad, solventando así los problemas inherentes, a la planificación, regularización, tenencia y uso del suelo, mediante un eficiente catastro multifinalitario, y un moderno sistema de recaudación fiscal.

Las necesidades de vivienda son solventadas mediante proyectos de inversión público-privado, con el incentivo fiscal, reglamentación de los solares desocupados, no construidos, de carácter edificable, generando un crecimiento y desarrollo ordenado de infraestructura social, satisfaciendo la demanda cuantitativa y cualitativa en la adquisición de una vivienda. Para este crecimiento urbanístico de vivienda, se estima la construcción de viviendas verticales, con el fin de brindarle a la ciudad, una mejor imagen urbanística y parasatisfacer a la población de todos los servicios y equipamientos básicos.

El equipamiento de la ciudad se desarrolla de forma satisfactoria para la población, con un reordenamiento en cuanto a ubicación, capacidad de servicio, y con el establecimiento de una normativa basada en las necesidades que presentan los barrios y colonias de la ciudad. Entre los principales equipamientos de la ciudad, tenemos los siguientes.

- Nuevas instalaciones del Hospital Regional del Sur, centros de salud, clíperes, clínicas y hospitales de atención privada distribuidos en toda la ciudad.

- Reubicación y construcción del nuevo cementerio general.

- Reordenamiento de las zonas comerciales, de servicios y financiera de la ciudad.

- Reordenamiento del sector comercial, formal e informal, en una nueva terminal de abastos.

- Preservación y ampliación de las áreas verdes y recreativas. 


\section{Componente de Infraestructuras}

El escenario óptimo para este componente, abarca las áreas en desarrollo y crecimiento, tanto comercial, industrial, residencial, logístico, entre otros, en cuanto al suministro de las infraestructuras de servicios básicos, de mitigación de desastres naturales, de accesibilidad y conectividad de la ciudad.

Para el sistema de conectividad, accesibilidad y transporte, en el año 2034, deberá funcionar de la siguiente forma:

- Implementación de los proyectos de mejoras y ampliación de los ejes carreteros CA-1, CA-3, Carretera hacia Marcovia, y Anillo Periférico. Esto implica toda la estructura vial, capa de rodadura, cunetas, señalización, calzada, alcantarillado, entre otras.

- Espaciamiento adecuado del derecho de vía con sus respectivas restricciones en las construcciones varias.

- Construcción de un nuevo tramo carretero en el sector oeste de la ciudad, en complementariedad con el anillo periférico, que servirá de alivio al tráfico pesado de transporte que se dirige hacia la frontera con Nicaragua.

- Implementación de una clasificación de calles y avenidas, con las condiciones requeridas de funcionalidad, en cuanto a medidas, señalización, drenaje, accesos y pavimentación.

- Ejecución de los proyectos de mantenimiento, tratamiento de calles no pavimentadas, accesibilidad, limpieza de cunetas, drenajes y derechos de vía.

- Implementación de proyectos de terminales del transporte público urbano e interurbano, con ampliación y distribución ordenada de nuevas rutas del servicio de transporte.

- Proyectos de construcción de alivios de tráfico en los tramos que conectan a los ejes carreteros CA-1, CA-3, carretera a Marcovia, sector centro y de los mercados.

- Proyectos de infraestructuras de mitigación de riesgos naturales, en las áreas de inundación de los ríos Choluteca y Sampile, y de posibles deslizamientos y deslaves en ríos, quebradas y zonas de alta pendiente, en los alrededores de la ciudad. 
- Restauración de la infraestructura pluvial, en cunetas y quebradas embauladas, alcantarillado y drenaje de calles.

En relación a la infraestructura de servicios básicos se contempla lo siguiente:

- Nuevas infraestructuras de los servicios sanitarios de la ciudad (agua potable, alcantarillado sanitario y recolección de desechos sólidos) proporcionando la cobertura total de los barrios y colonias, y su eficiente prestación de servicios de calidad.

- Se contará con la operación de un nuevo relleno sanitario, con las normas de calidad y los estándares de funcionalidad óptima, haciendo un uso adecuado de la disposición final de los desechos sólidos.

- Infraestructuras modernas en el servicio de energía eléctrica y telecomunicaciones, con una amplia cobertura y capacidad del suministro.

\section{Componente Socioeconómico}

La actividad económica de la ciudad radicara en la prestación de servicios, generación de nuevos empleos con la instalación de pequeñas, medianas y grandes empresas, de capital local, nacional y extranjero.

El rubro del turismo generara oportunidades de desarrollo local, posicionando a la ciudad entre las principales ciudades con un importante turismo colonial, así como también, en la prestación competitiva de los servicios hoteleros de la región.

La prestación de servicios públicos de salud será el mejor de la región, contando con un hospital regional con las capacidades de atención e infraestructura necesarias para satisfacer las demandas de la población urbana y rural, contando además con nuevas especialidades ,con personal técnico, administrativo y profesional, debidamente capacitados que estén comprometidos en ofrecer el mejor servicio de calidad. Se contará con una amplia red hospitalaria y de clínicas de índole privado, esto para generar una asistencia médica de calidad y competitiva, en cuanto a precios, atención y servicios, donde la población pueda acceder por comodidad y disponibilidad de recursos.

El sistema de educación pública ofrecerá una cartera amplia de ofertas formativas de calidad, la infraestructura e insumos necesarios para albergar a la población 
estudiantil, y el compromiso social de egresar a profesionales con capacidades de desempeño y conocimiento, de gran potencial laboral y profesional.

La organización y participación social de la población ha sido el determinante en las principales decisiones y acciones por parte de las autoridades locales, para la ejecución y fiscalización de los proyectos de inversión social, así como también en el acompañamiento de los organismos cooperantes y organizaciones no gubernamentales, con incidencia en el desarrollo sostenible de la ciudad, sumado a esto, la concientización social, en los temas de recaudación fiscal, cuidado de los recursos naturales y del capital físico con que cuenta la ciudad.

\section{Escenario Intermedio Ciudad de Choluteca}

Escenario Intermedio o concertado, en el que se integran los elementos de desarrollo y condiciones para el mismo, por medio del consenso de los actores claves, mediante los talleres de socialización y participación ciudadana realizados en la ciudad. En este escenario se pretende establecer una imagen futura consensuada de la ciudad, con el involucramiento de las autoridades locales, instituciones gubernamentales y no gubernamentales, población organizada, empresa privada, entre otros, con el fin de establecer una prospectiva clara del desarrollo y crecimiento sostenible de la ciudad, siendo este el resultado, del Modelo Territorial Futuro deseado para el año 2034 de la ciudad de Choluteca, considerando a los otros dos escenarios, en un $60 \%$ de las metas y alcances del escenario optimo, y un $40 \%$ correspondiente al escenario tendencial.

\section{Componente Ambiental}

Partiendo de una combinación de los elementos establecidos por los dos escenarios anteriores, y los consensos establecidos en las mesas del taller de prospectiva, en relación a las áreas a desarrollar y de crecimiento urbano de la ciudad, se describen a continuación:

\section{Componente Ambiental y gestión de Riesgos}

- Se considerarán como áreas de conservación ambiental los corredores de inundación del Río Choluteca y Río Sampile, se reforestarán dichas zonas generando un cinturón verde de la ciudad optimizando la imagen urbana, así como las condiciones de calidad del aire de la ciudad. 
- Los asentamientos con servicios básicos mínimos se reducirán, aumentando la cobertura de alcantarillado sanitario cerca del $40 \%$ en la ciudad, y así reduciendo la contaminación por aguas residuales en los Ríos Choluteca y Sampile.

- La calidad y continuidad del agua potable a través de tubería aumentara cerca de $60 \%$ de cobertura dentro de la ciudad, reduciendo las enfermedades producto de consumo de agua contaminada, especialmente por coliformes fecales.

- Los asentamientos en zonas de inundación se deberán desincentivar reduciendo al mínimo los servicios básicos en ellos.

- Se respetará el uso del suelo en los alrededores de la cuidad, las futuras urbanizaciones que se construyan en antiguas zonas agroindustriales, deberán de evitar construir pozos de extracción de agua potable en dichas zonas 0 considerar los mecanismos para la potabilización del agua, y así brindar agua óptima para consumo humano.

- El aumento de la cobertura en el sistema de recolección de desechos sólidos en la ciudad de Choluteca, mejorara las condiciones ambientales de la urbe especialmente dentro del centro de la ciudad, permaneciendo aún pendiente la recolección en las zonas periféricas, sin embargo esto reducirá grandemente la practicas poco amigables con el medio ambiente que se han dado hasta la actualidad, además aumentara la concientización de la población en tener una adecuada disposición final de los desechos sólidos.

- Se considerará la construcción de un sistema de clasificación de desechos sólidos, de este modo se pretenderá optimizar la disposición final de los desechos sólidos y aumentar la vida útil del relleno sanitario.

\section{Componente Urbanismo Vivienda y Equipamiento}

- La buena voluntad política en aplicar las normativas de ordenamiento territorial vigente, así como una correcta coordinación intergubernamental y regulación del uso del suelo, evitara la consolidación y el surgimiento de nuevos asentamientos en zonas desfavorables o de inundación. 
- Los asentamientos establecidos en áreas no aptas para uso habitacional, como ser zonas inundables, deberán de desincentivarse en cuanto a su crecimiento, reduciendo al mínimo los servicios básicos, y evitando en lo posible la creación de nuevos proyectos, de no lograrse la reducción de la población en estas zonas vulnerables, habrá que realizar las medidas de mitigación y prevención de desastres correspondientes en cuanto a obras civiles para reducir el impacto de posibles eventos meteorológicos extremos.

- Será necesario incentivar la densificación de la población dentro de la ciudad, especialmente en solares baldíos y zonas de baja densidad poblacional, tomando el $60 \%$ del área del escenario optimo, y que corresponderá a 462 hectáreas, mientras que el $40 \%$ restante será tomada del área perteneciente al escenario tendencial, la cual representará un área de 908 hectáreas.

- Se respetará al máximo el derecho de vía de los ejes carreteros pensando en una ampliación futura de la calzada de la carretera, esto mejorará la visibilidad de los conductores reduciendo el peligro de accidentes viales.

- La mayoría de terrenos en la ciudad de Choluteca son de carácter privado, por ello los planes de vivienda social estará limitados a que el solicitante tenga su predio, pero podría existir una gestión por parte de la alcaldía para adquirir terrenos a bajo costo que impulsen la construcción de vivienda de tipo básico, de este modo se disminuirá considerablemente los problemas de déficit cuantitativo y cualitativo que actualmente proliferan en la ciudad.

- Se tomarán las acciones respectivas a fin de mejorar las condiciones de los mercados San Antonio, Inmaculada Concepción, El Rápido y Terminal de buses, del mismo modo se gestionará por parte de la alcaldía la construcción de un nuevo mercado que brinde las condiciones óptimas tanto para los vendedores como para los consumidores, en este nuevo mercado se deberá reubicar la gran cantidad de vendedores ambulantes que obstaculizan el libre tránsito tanto peatonal como vehicular.

- Se deberá gestionar la construcción de un nuevo cementerio público que brinde las necesidades de la población.

- Al equipamiento recreativo y deportivo se le deberá de añadir un toque ambiental, aumentando el área verde en ellos, reduciendo así las denominadas islas de calor en la ciudad y mejorando la imagen urbana, también se deberá brindar 
un mantenimiento rutinario al equipamiento recreativo que se encuentran en la periferia de la ciudad.

- La alcaldía tendrá que dar el paso para crear un catastro multifinalitario que realmente brinde las condiciones de planificación territorial que impulse el desarrollo adecuado de la ciudad, permitiendo la mejora en la recaudación fiscal y que a su vez servirá para impulsar nuevos proyectos sociales.

\section{Componente de Infraestructuras}

Considerando los dos escenarios anteriores, más el consenso de los diferentes actores en el taller de prospectiva de la ciudad de Choluteca para el año 2034, se establecen los siguientes objetivos para construir un Modelo Territorial Futuro deseado, en el sector de las infraestructuras, las cuales deberán funcionar de la siguiente forma:

- Gestionar por parte de las autoridades locales y departamentales al gobierno central, el mantenimiento, ampliación y cuidado de los derechos de vías de los principales ejes carreteros que conectan a la ciudad (CA-1 y CA-3), dado la importancia que tienen para el país y la región centroamericana.

- La red vial principal pavimentada de la ciudad, mejorara de manera considerable, gracias a la inversión público-privado, en primer lugar, por parte de la municipal, con un eficiente sistema de recaudación fiscal y plan de inversión en infraestructura vial, en conjunto, con el aporte económico y logístico de la empresa privada, para la implementación de estas acciones. En cuanto el mantenimiento en sus principales avenidas y bulevares seguirá, de manera preventiva y periódica, para ofrecerle a la población y los visitantes, las mejores condiciones de accesibilidad y comodidad al transitar.

- La red de calles de los barrios y colonias aun no pavimentados, se irán construyendo con la participación activa de los pobladores y municipalidad, en cuanto a recursos propios, a la gestión financiera y de cooperación externa, mejorando las condiciones de vida de los pobladores y dándole a la ciudad, un desarrollo urbanístico y de crecimiento económico importante en la región.

- Restauración de las infraestructuras pluvial, en cunetas y quebradas embauladas, alcantarillado y drenaje de calles, esto como medidas de mitigación a los problemas de inundación por las lluvias torrenciales que 
afectan a la ciudad en las épocas de invierno, sumado la concientización y participación de la población, en el cuidado y mantenimiento de limpieza y no obstruir estas infraestructuras de desagües.

- Ejecución de proyectos de construcción de alivios de tráfico en los tramos que conectan a los ejes carreteros CA-1, CA-3, carretera a Marcovia, sector centro y de los mercados.

- Señalamiento vial y semaforización de las principales calles y avenidas de la ciudad.

- Reubicación del aeropuerto de la ciudad, dado que la actual instalación, ha sido absorbida por los proyectos residenciales, limitando su ampliación y condiciones de funcionalidad requeridos, además de encontrarse, en la zona de expansión y desarrollo urbano, por lo será destinando dicha instalación, a una terminal de transporte y abasto, que satisfagan a la población albergada en ese sector de la ciudad para el año 2034.

- Implementación de medidas en la construcción de infraestructuras de mitigación de riesgos, por inundación (rio Choluteca y Sampile), deslizamientos, sequias, entre otros de carácter eventual.

\section{Infraestructura de servicios básicos:}

- Con la implementación de las acciones e intervención oportuna por parte de las autoridades locales y el marco legal institucional nacional y local, en relación a una densificación y ordenamiento urbano proyectado de los asentamientos humanos, se lograran hacer esfuerzos en solventar a los barrios y colonias, que adolecen de los servicios públicos, disminuyendo considerablemente, los déficit de cobertura y dotación diaria de agua potable, acceso a la red de aguas negras, energía eléctrica, telecomunicaciones y servicio de recolección de desechos sólidos, esto con proyectos de restauración, mantenimiento y construcción de las infraestructuras necesarias para suplir las demandas de la población proyectada.

- Mejora en el suministro y tratamiento del agua potable, en cuanto a la calidad de potabilización, captación, distribución y conexión, así como también, con el 
cumplimiento de las medidas sanitarias de consumo de las aguas subterráneas, en los sectores que se abasteces por sistemas de pozos.

- Ampliación y mejoras de las condiciones del sistema de saneamiento, en relación a la captación, deposición y tratamiento de las aguas servidas, así como también, los sectores que cuentan con sistemas individuales de letrinas y pozos sépticos, minimizando los riegos de contaminación de los suelos, aguas superficiales y subterráneas.

- Ampliación y restructuración del relleno sanitario, en cuanto a captación, deposición y tratamiento de los desechos sólidos y líquidos, cumpliendo con todas las especificaciones técnicas, operativas y ambientales requeridas para una ciudad.

\section{Componente Socioeconómico}

La actividad económica principal de la ciudad, será la prestación de servicios, creando las condiciones adecuadas para la inversión privada, mediante políticas estratégicas de incentivos fiscales y promoción del sector turismo del casco histórico, parques, museos, cultura y tradición de la ciudad, con la incorporación de un comité de turismo, integraos por todos los actores claves y de interés.

Los esfuerzos en el sector salud pública, se coordinarán con el involucramiento activo de la sociedad civil organizada y autoridades locales, mediante programas de cobertura asistencial en barrios y colonias, prevención y concientización de la población, además de la gestión de proyectos de reconstrucción, mantenimiento y equipamiento del hospital regional del sur, y del resto de los centros de asistencia inmediata de la ciudad.

En cuanto al sistema educativo, se requiere de la participación activa de los padres de familia, así como de las organizaciones sociales, para fortalecer los procesos de restructuración del sistema educativo, desde los niveles primarios hasta el nivel superior, donde se requiere una diversificación de carreras técnicas profesionales, en las aéreas productivas, de servicio y científicas, que requiere la ciudad, a fin de volverla más competitiva, y en donde su población joven en su mayoría, impulsen el desarrollo socioeconómico de la ciudad. 
Si bien es cierto, que las infraestructuras generan progreso para las ciudades, el desarrollo sostenible, depende de su población, de cómo está se encuentra estructurada, equipada, y lo más importante, como está organizada. El hecho que la ciudad cuente con cualquier tipo de organización social, ya sea, legal, institucional o religiosa, bastara para generar los cambios positivos y de desarrollo deseado por cada ciudadano, y esto es uno de los potenciales con que cuenta actualmente la ciudad, por lo que la construcción del Modelo Territorial Futuro, concertado, dependerá en su mayoría, de este factor.

\section{CONCLUSIONES}

1. Se detectaron 48 problemas en la ciudad de Choluteca, de los cuales 14 corresponden al sector ambiente, 9 al sector de infraestructura, 14 al sector de urbanismo, vivienda y equipamiento y 11 al sector de socio economía.

2. Se encontraron 23 potencialidades en la ciudad de Choluteca, de las cuales 3 corresponden al sector ambiente, 6 al sector de infraestructura, 6 al sector de urbanismo, vivienda y equipamiento y 8 al sector de socio economía.

3. Con los problemas y potencialidades encontradas se elaboró el Modelo Urbano Actual de la ciudad de Choluteca.

4. Se construyeron los tres escenarios futuros para la ciudad de Choluteca al año 2034 estimando que para ese año habrá una población de 184,350 habitantes.

\section{AGRADECIMIENTOS}

Agradecemos el apoyo de la Corporación Municipal de Choluteca, a Visión Mundial y a todos los asistentes a los talleres que se realizaron en la ciudad de Choluteca, ya que sin ellos no hubiera sido posible realizar este estudio. 


\section{BIBLIOGRAFÍA}

- Banco Interamericano de Desarrollo (BID). (Julio de 2014). Guía Metodológica de Iniciativa de Ciudades Emergentes y Sostenibles., Segunda Edición. Recuperado el Abril de 2015, de www.iadb.org

- Cauas, D. (s.f.). Definición de las variables, enfoque y tipo de Investigación.

- Glosario de Términos de la propuesta del Reglamento de Zonificación Ecológica y Económica. (s.f.). Obtenido de http://www.iiap.org.pe/avances/poa/ GLOSARIO-Reglamento.pdf

- Godet, M. (DIR.), Bassaler (Nathalie), Monti (Régine), Richou (Saphia) (COLL.), 2005, Entreprises et territoires, trames des ateliers de prospective stratégique, CNAM, Lipsor

- Jouvenel H. (1993) « Sur la méthode prospective : un bref guide méthodologique », Futuribles, n¹79

- Reques Valeasco, P., \& Rodríguez Rodríguez, V. (s.f.). Prospectivas Demográficas y Territoriales. Treballs de la Societat Catalana de Geografía, XI.

- Soms, E., \& otros. (Enero de 2005). PROSPECTIVA Y CONSTRUCCIÓN DE ESCENARIOS PARA EL DESARROLLO TERRITORIAL. (G. F. S.A., Ed.) Santiago, Chile. 